\title{
PERANCANGAN DESAIN INTERFACE APLIKASI SMARTPHONE UNTUK MENU DI AGRA ROOFTOP DENGAN TEORI NIRMANA
}

\author{
Yohanes Anton Kurniawan', Martin Setyawan ${ }^{2}$ \\ 1,2Program Studi Desain Komunikasi Visual, Fakultas Teknologi Informasi, \\ Universitas Kristen Satya Wacana \\ yohanesanton24@gmail.com¹, martinsetyawan@gmail.com².
}

\begin{abstract}
AGRA Rooftop is one of the highest lounges in Central Java. Its operating hours at AGRA Rooftop is between 17:00 - 00:00. The difficulty experienced by AGRA Rooftop consumers is reading the menu at night because the lighting in AGRA Rooftop is designed to enjoy the sunset or the city of Solo at night. The design of the new menu interface is expected to help consumers to read and to understand the menus as well as to help the promotion the smartphone. The research method and design strategy used in this research is prototyping and cyclic strategy. Interface design has been tested and the results show that the interface is quite interesting and helps consumers to choose and to understand the menu.
\end{abstract}

Keywords: interface design, menu, AGRA Rooftop

\begin{abstract}
Abstrak: AGRA Rooftop merupakan salah satu lounge tertinggi di Jawa Tengah. Jam operasional di AGRA Rooftop antara pukul 17.00 - 00.00. Kesulitan yang dialami oleh konsumen AGRA Rooftop adalah membaca menu yang ada pada waktu malam karena pencahayaan yang ada di AGRA Rooftop didesain untuk menikmati sunset atau pemandangan kota Solo pada waktu malam. Perancangan interface menu yang baru diharapkan dapat membantu konsumen untuk membaca dan mengerti menu yang ada serta dapat membantu promosi yang dimiliki kedalam smartphone. Metode penelitian dan strategi perancangan yang digunakan dalam penelitian ini adalah prototype dan cyclic strategy. Perancangan interface sudah diujikan dan didapatkan hasil bahwa interface yang ada sudah cukup menarik dan membantu konsumen dalam memilih dan memahami menu yang ada.
\end{abstract}

Kata kunci: desain interface, menu, AGRA Rooftop

\section{LATAR BELAKANG}

AGRA Rooftop, merupakan lounge pertama yang memiliki lokasi tertinggi di kota Surakarta. AGRA Rooftop dibuka pada pada bulan April 2016 dan terletak di lantai 29, Hotel Alila Solo. Lounge ini memiliki lokasi yang cukup menarik untuk menikmati sunset di kota Surakarta atau menikmati keindahan kota di malam hari. AGRA Rooftop memiliki jam operasional mulai jam 5 sore sampai dini hari. AGRA Rooftop didesain sebagai tempat untuk bersantai sekaligus menikmati pemandangan sunset kota Solo hingga waktu malam. Agar konsumen dapat menikmati pemandangan kota Solo pada waktu malam, maka pencahayaan di

Received on $: 15 / 05 / 2020$

Revised on : 20/12/2020

Accepted on : 23/03/2021
AGRA Rooftop tidak dibuat terlalu terang.

Hal tersebut menimbulkan masalah tersendiri bagi konsumen. Permasalahan yang dialami oleh konsumen adalah saat memilih menu pada malam hari, menurut staf dari AGRA Rooftop dan wawancara dari beberapa konsumen bahwa 7 dari 10 pengunjung mengalami kesulitan untuk membaca menu yang ada pada malam hari karena kurangnya pencahayaan. Pengalaman lain yang dirasakan saat membaca menu yang ada menurut konsumen adalah saat membaca menu menjadi kurang mudah karena harus membalik kertas dan jumlahnya tidak sedikit. Permasalahan yang dihadapi juga oleh AGRA Rooftop adalah biaya cetak 
yang tidak sedikit untuk mengganti menu.

Perancangan interface untuk dijadikan aplikasi sudah pernah dilakukan oleh Wisnu Pramudita (2014) yang membuat katalog untuk Meercut Distro \& Clothing. Selanjutnya Andre Christian (2013) yang membuat katalog penjualan furniture. Kusnawi Kintar (2015) dalam penelitiannya juga membahas mengenai penggunaan user interface dan user experience, sehingga membantu pengguna aplikasi untuk mempermudah mendapatkan informasi perusahaan di dalam media online secara jelas dan menarik bagi pembeli produk dan calon pengguna

Penelitian ini diadakan untuk mengubah menu yang awalnya dicetak dalam kertas dibuat menjadi bentuk digital sehingga dapat diakses melalui smartphone. Aplikasi dalam smartphone memerlukan adanya sebuah interface untuk menjalankan aplikasi tersebut. Oleh karena itu, penelitian ini diadakan untuk merancang interface yang nantinya akan diterapkan dalam aplikasi tersebut. Penggunaan teori nirmana dalam perancangan ini nantinya akan digunakan sebagai dasar penentuan desain yang akan digunakan, baik itu dari komposisi, warna serta elemen yang akan digunakan nantinya. Penggunaan smartphone dapat menjadi inovasi baru bagi AGRA Rooftop selain untuk membantu menghemat biaya cetak saat ada perubahan menu karena jika ada perubahan tidak perlu untuk mencetak kembali melainkan dapat diubah dan aplikasi yang ada tinggal diperbarui saja, sekaligus dapat menghemat waktu yang dimiliki oleh konsumen karena melalui smartphone pengunjung dapat memilih menu sebelum datang ke AGRA Rooftop. Perancangan ini juga bermanfaat bagi AGRA Rooftop untuk membantu sebagai media promosi kepada konsumen atau masyarakat. Penggunaan smartphone juga cukup efektif karena selain tingkat cahaya yang dapat diatur, pengunjung juga dapat melihat foto produk yang akan dipilihnya nanti.

\section{METODE PENELITIAN}

Metode yang akan dipakai adalah penelitian metode prototype, yakni suatu proses yang memungkinkan developer membuat sebuah model software, metode ini baik digunakan apabila client tidak bisa memberikan informasi yang maksimal mengenai kebutuhan yang diinginkannya (Yurindra, 2011:404)

Strategi yang digunakan dalam penelitian ini adalah Cyclic strategy, Cyclic strategy atau strategi ini pada dasarnya memiliki prinsip yang sama dengan linear strategy, hanya saja pada strategi ini ada kalanya suatu tahap perlu diulang kembali untuk menampung umpan balik (Sarwono, 2007: 28). Tahapan penelitian dengan cyclic strategy dapat dilihat di Gambar 1.

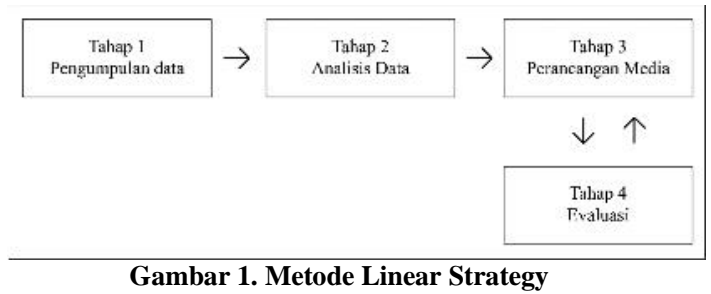

[Sumber : Sarwono, 2007]

Berdasarkan bagan diatas, linear strategy terbagi menjadi 4 tahapan yaitu tahap identifikasi masalah, tahap analisis data, tahap perancangan dan tahap pengujian. Tahapan pengumpulan data dilakukan dengan wawancara kepada outlet manager AGRA Rooftop dan observasi pada lokasi AGRA Rooftop. Tahap analisis data dilakukan dengan menganalisis data verbal, visual dan menentukan karakteristik yang akan dituangkan pada perancangan interface. Tahapan selanjutnya adalah tahapan perancangan, dalam tahapan perancangan ini terbagi menjadi beberapa bagian yakni pembuatan konsep, perancangan kemasan, perancangan katalog serta hasil perancangan kemasan dan katalog. Tahapan selanjutnya adalah tahapan pengujian, pengujian dilakukan kepada pemilik batik, desainer kemasan dan responden selaku target konsumen dari AGRA Rooftop.

\section{HASIL}

\section{Tahap Identifikasi Masalah}

Tahap pertama dalam penelitian ini 
adalah identifikasi masalah berdasarkan permasalahan yang ada mengenai masalah yang ada di dalam penelitian ini. Observasi dilakukan juga secara langsung di AGRA Rooftop. Berdasarkan observasi yang dilakukan, data lain yang didapatkan adalah corporate identity, promo apa saja yang ada di AGRA Rooftop selama satu minggu, view yang dimiliki AGRA Rooftop waktu sore dan foto lokasi AGRA Rooftop pada waktu sore dan pada waktu malam hari. AGRA Rooftop menggunakan Instagram dan flyer sebagai media promosi.

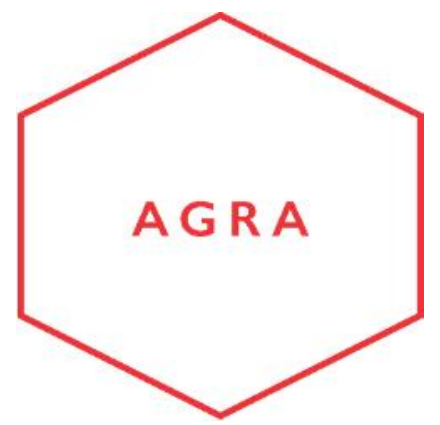

Gambar 2. Logo AGRA Rooftop

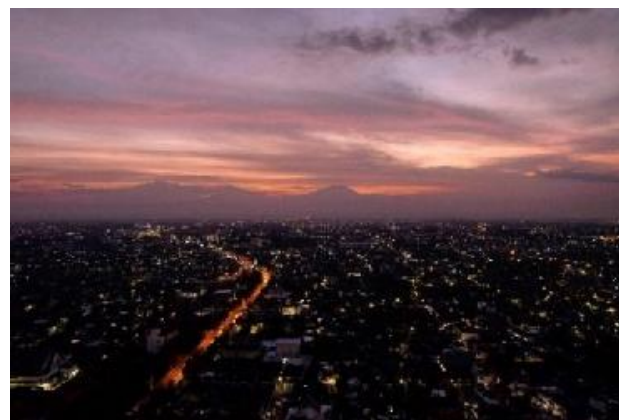

Gambar 3. View AGRA Rooftop Waktu Sore
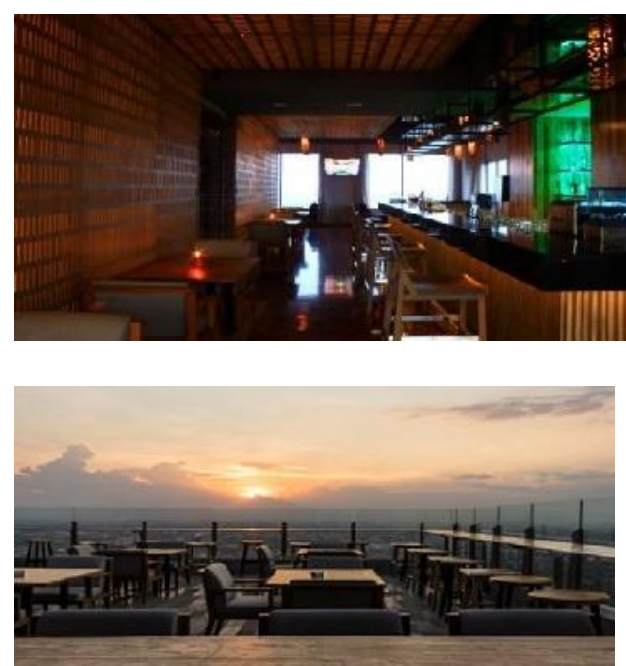

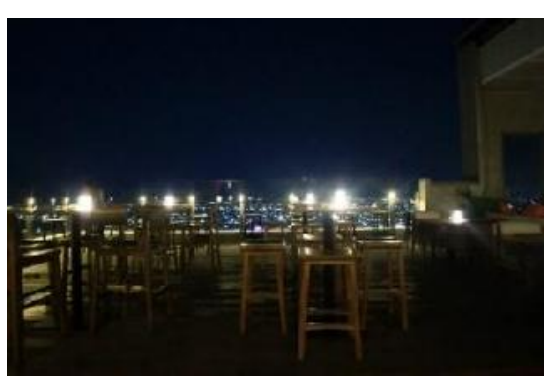

Gambar 4. Lokasi AGRA Rooftop

Tahap Analisis Data

Tahap kedua yaitu analisis data verbal dan visual, dalam tahapan ini menganalisis dan menentukan karakteristik yang akan dituangkan pada perancangan interface. Hasil wawancara yang dilakukan kepada 10 pengunjung AGRA Rooftop secara acak mengenai menu yang ada sebelumnya, 7 dari 10 pengunjung mengalami kesulitan untuk membaca menu yang ada pada malam hari karena kurangnya pencahayaan. Pengalaman lain yang dirasakan saat membaca menu yang ada menurut konsumen adalah saat membaca menu menjadi kurang mudah karena harus membalik kertas dan jumlahnya tidak sedikit. Permasalahan yang dihadapi juga oleh AGRA Rooftop adalah biaya cetak yang tidak sedikit untuk mengganti menu. Pada analisis ini didapatkan bahwa menu yang ada sekarang secara keseluruhan belum bisa dipahami oleh konsumen AGRA Rooftop. Analisis data lebih mengarah kepada penarikan kesimpulan berdasarkan permasalahan yang ada.

\section{Tahap Perancangan}

Tahap ketiga yaitu tahap perancangan. Pada tahapan perancangan ini, akan dilakukan pemetaan analisis yang sudah dibuat untuk menjadi dasar proses brainstorming konsep perancangan interface. Untuk konsep dari perancangan desain interface ini menampilkan tampilan yang user interface yang minimalis agar dapat mudah dipahami oleh konsumen pada saat penggunaannya. Pada perancangan ini, gaya desain yang akan digunakan merupakan gaya flat design. Penggunaan gaya desain ini dipilih karena 
dalam penerapannya desain yang digunakan cukup sederhana dan mudah dipahami.

Konsep perancangan pada awal aplikasi ini akan ada login screen agar konsumen AGRA Rooftop terdata, dan mempermudah untuk menyebarkan promosi acara yang akan diadakan oleh AGRA Rooftop nantinya. Pada menu utama terdapat enam buah menu, dua menu untuk memilih menu makanan dan minuman, sebuah tombol untuk bagian promosi / event yang ada di AGRA Rooftop, baik promo selama satu minggu maupun event khusus yang diadakan di AGRA Rooftop. Pada bagian bawah aplikasi ini nantinya akan ada tombol untuk booking tempat di AGRA Rooftop, tombol untuk menuju Instagram dari AGRA Rooftop. Serta menu untuk menjelaskan tentang AGRA Rooftop, jam operasional, dan peraturan secara umum yang berlaku di AGRA Rooftop. Tombol ini juga berfungsi untuk bagian contact us, sehingga pengunjung dapat menyampaikan kritik, pujian, opini, ide dan gagasan kepada AGRA Rooftop melalui telepon dan email. Dan untuk latar belakang aplikasi ini akan digunakan foto suasana dari AGRA Rooftop waktu sunset.

Penggunaan warna yang akan digunakan dalam aplikasi ini nantinya adalah warna hitam, merah dan putih dengan susunan RGB :

Hitam $=R=0 \quad G=0 \quad B=0$

Merah $=\mathrm{R}=237 \mathrm{G}=50 \mathrm{~B}=55$

Putih $=\mathrm{R}=255 \mathrm{G}=255 \mathrm{~B}=255$

warna ini dipilih karena warna ini merupakan corporate identity dari AGRA Rooftop.

Jenis font yang digunakan dalam aplikasi ini adalah Sans Serif dengan tipe Gill Sans. Font ini digunakan karena merupakan corporate identity dari AGRA Rooftop.

Ukuran yang digunakan masing masing icon dalam aplikasi ini nantinya 490 x 190px. Ukuran ini diambil karena nantinya dapat menggunakan banyak menu tanpa mengorbankan kenyamanan dalam penggunaan aplikasi ini.

Selanjutnya adalah pembuatan sketsa. Dalam pembuatan sketsa terdapat untuk layout tampilan menu beserta icon yang akan digunakan nantinya dalam pembuatan aplikasi. Sketsa untuk icon dan layout interface dapat dilihat pada Gambar 5 dan Gambar 6.

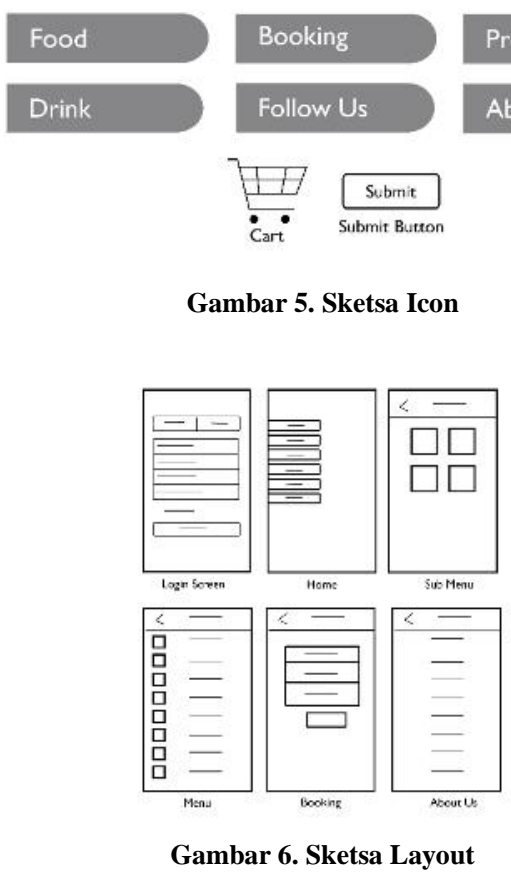

Pada bagian login screen, dan booking diletakkan di bagian tengah supaya mudah untuk dibaca mengenai apa saja yang akan di input konsumen. Pada bagian home screen, peletakan menu berada di sisi sebelah kiri agar konsumen dapat menggunakan dengan satu tangan. Pada bagian kategori makanan dipilih tampilan grid karena foto untuk menjelaskan jenis apa saja makanan apa saja yang berada dalam kategori tersebut lebih jelas terlihat. Sedangkan untuk bagian menu dipilih layout secara list karena informasi yang ada dapat disampaikan secara jelas baik itu nama menu, harga, bahan yang digunakan serta tampilan menu yang dipilih.

\section{Pembuatan Button Menu}

Button menu bertujuan untuk memudahkan konsumen saat memilih bagian untuk menu makanan, minuman, promosi, memesan tempat, dll. Tahap proses pembuatan icon dan hasil icon dapat dilihat pada Gambar 7 dan Gambar 8. 


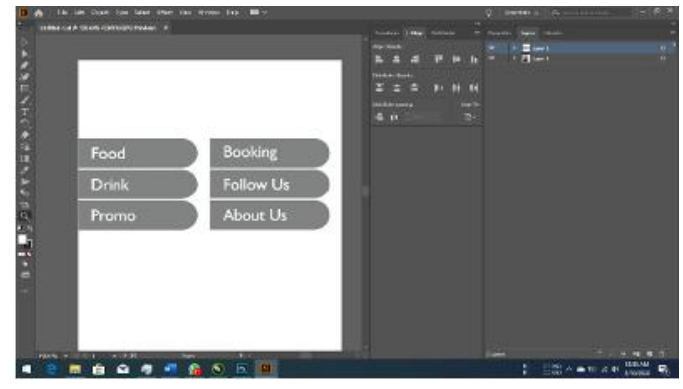

Gambar 7. Proses Pembuatan Icon

\begin{tabular}{|l|}
\hline Food \\
\hline Drink \\
\hline
\end{tabular}

\begin{tabular}{|l|}
\hline Booking \\
\hline Follow Us \\
\hline
\end{tabular}

Promo

About Us

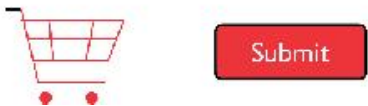

Gambar 8. Icon yang akan digunakan

\section{Pengambilan Foto}

Dilakukan pengambilan foto sesuai dengan konsep yang ada. Semua foto yang ada akan disimpan dalam bentuk RAW dan jpeg. Bentuk RAW nantinya akan digunakan pada proses selanjutnya, yaitu proses editing, sedangkan bentuk jpeg akan digunakan hanya sebagai preview saat memilih atau seleksi foto.

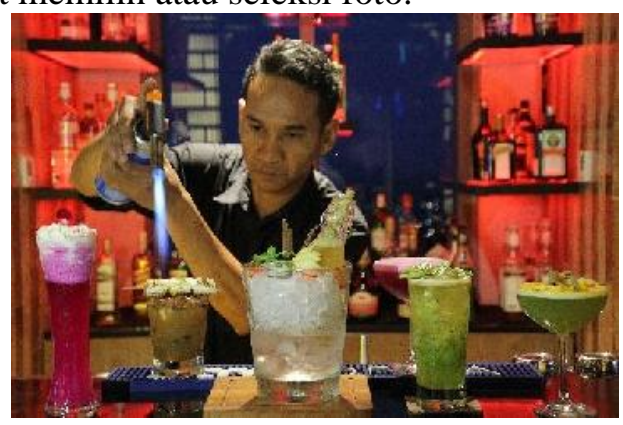

Gambar 9 Proses Pengumpulan Foto

\section{Seleksi Foto Dan Editing}

Dilakukan seleksi foto dari beberapa foto yang sudah diambil. Seleksi dilakukan dengan melakukan preview pada bentuk jpeg foto. Foto yang sudah terpilih kemudian akan di edit ulang file RAW yang ada menggunakan program khusus edit foto. Editing yang dilakukan hanya sebatas mengubah brightness, contrast, saturation dan cropping dari foto yang sudah ada supaya menjadi lebih terlihat menarik. Foto yang sudah diedit dan data verbal yang telah terkumpul akan dimasukkan ke dalam draft untuk dijadikan layout.

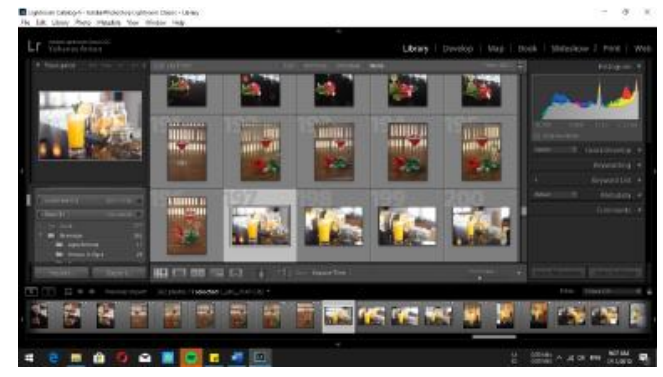

Gambar 10. Proses Editing Foto

\section{Pembuatan Desain Layout Aplikasi}

Pembuatan desain layout aplikasi dilakukan karena merupakan hasil akhir dan akan diujikan kepada staff dan tamu AGRA Rooftop. Tahap proses pembuatan layout interface dapat dilihat pada Gambar 11.

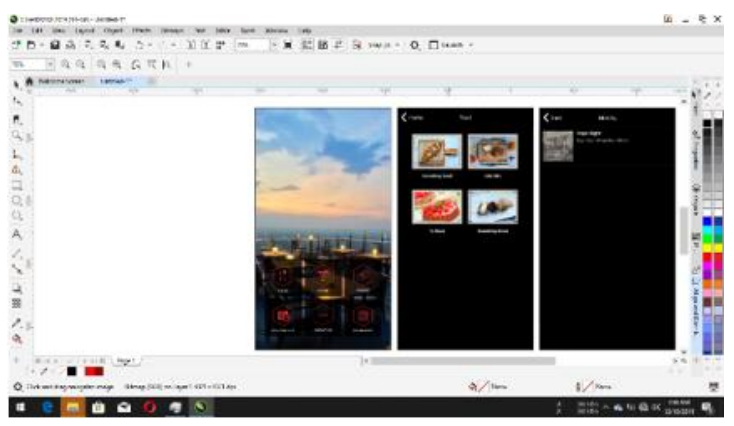

Gambar 11. Proses Pembuatan Layout Interface

Dalam desain ini digunakan warna merah untuk icon, dan font yang digunakan berjenis sans serif dengan tipe Gill Sans, serta menggunakan warna hitam sebagai background pada menu.

Pada login screen terdapat 2 bagian yaitu bagian sign up dan sign in. Pada login screen dapat dimanfaatkan sebagai pengumpulan data dari konsumen dan dapat sebagai data saat konsumen reservasi tempat. 


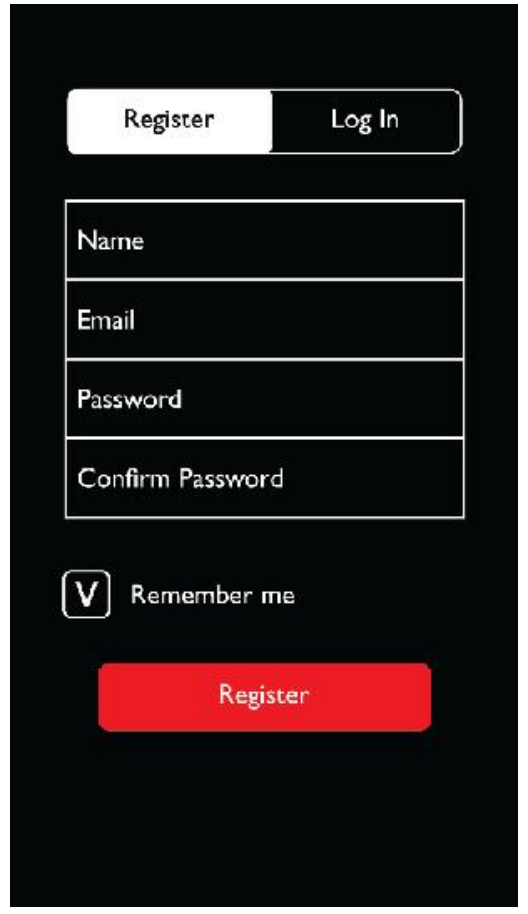

Gambar 12. Tampilan Login Screen [Sumber: Dokumentasi Penulis]

Pada menu utama terdapat background dari area outdoor dari AGRA Rooftop. Pada bagian ini terdapat 6 menu yaitu food, drink, promotion, booking, about us, dan follow us.

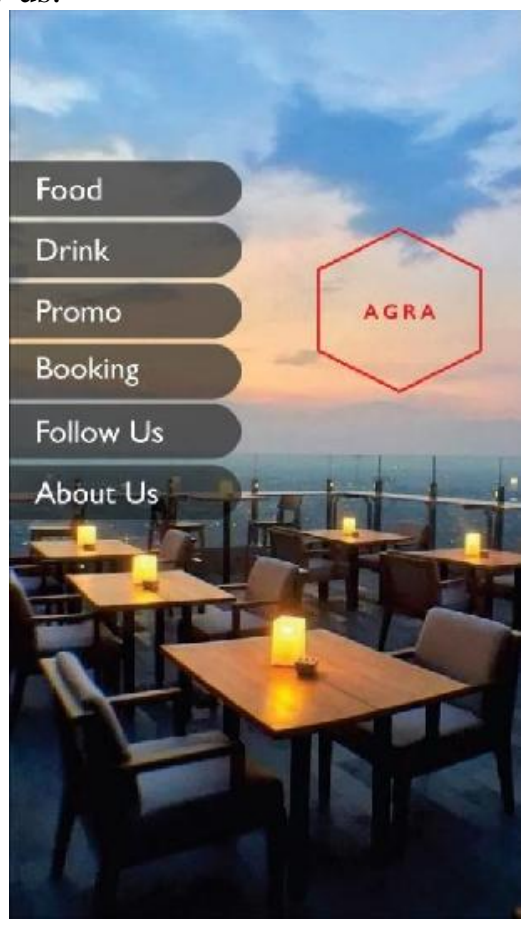

Gambar 13. Tampilan Menu Utama

Pada sub menu dari food, drink dan promotion terdapat pilihan untuk jenis menu selanjutnya. Dalam sub menu terdapat foto yang menggambarkan isi menu apa saja yang ada di dalamnya. Pada bagian menu kategori baik pada makanan, minuman dan promosi, terdapat foto menu dan flyer acara yang sedang berlangsung serta penjelasannya.
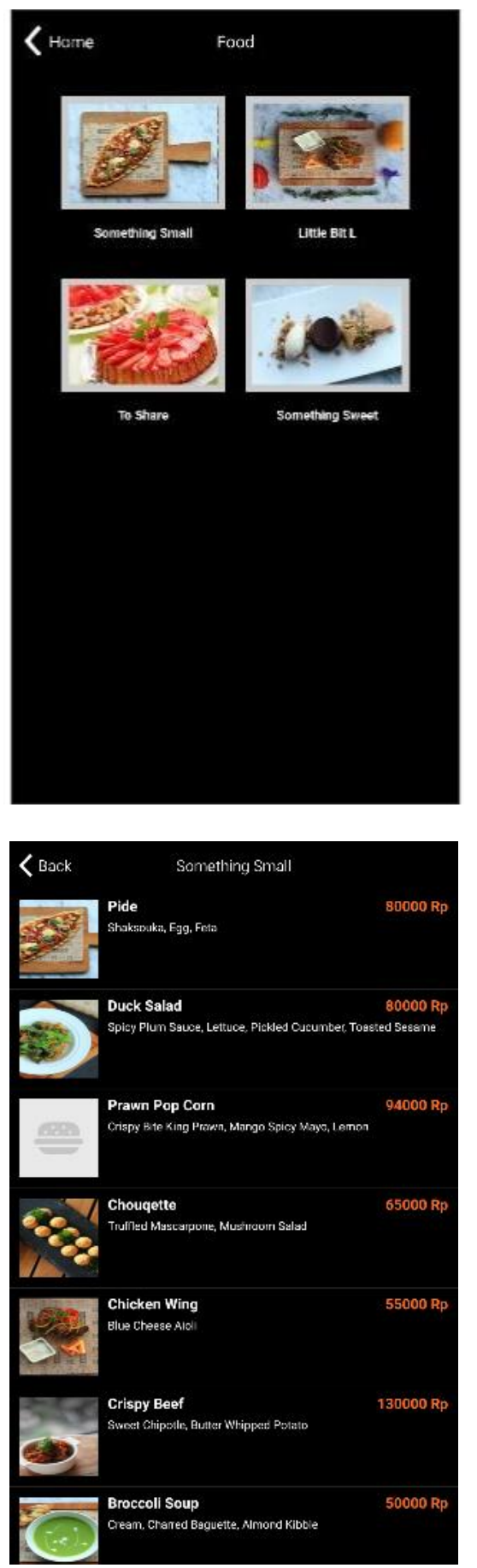

Gambar 14. Tampilan Sub Menu 
Pada bagian reservasi, terdapat kolom untuk konsumen menentukan tanggal, waktu dan jumlah konsumen yang akan pesan tempat di AGRA Rooftop. Layout untuk bagian reservasi dapat dilihat pada Gambar 15.

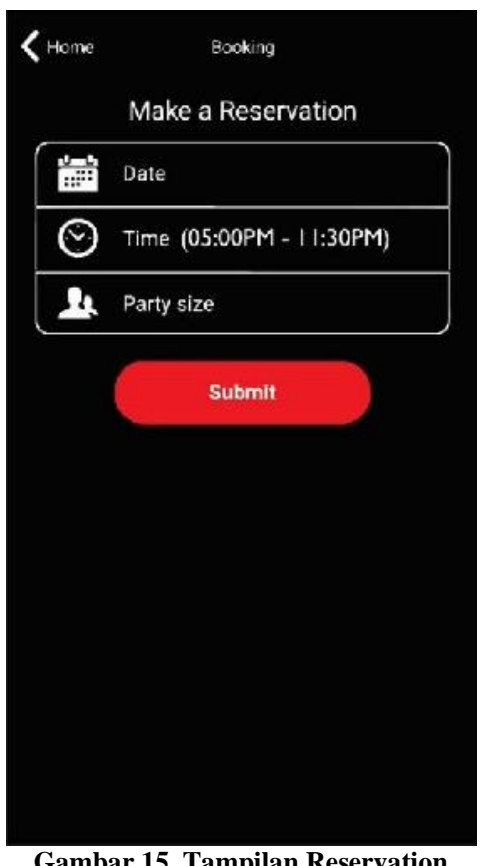

Pada bagian About Us merupakan penjelasan mengenai AGRA Rooftop baik jam operasional maupun peraturan yang berlaku di AGRA Rooftop. Layout untuk bagian reservasi dapat dilihat pada Gambar 16.

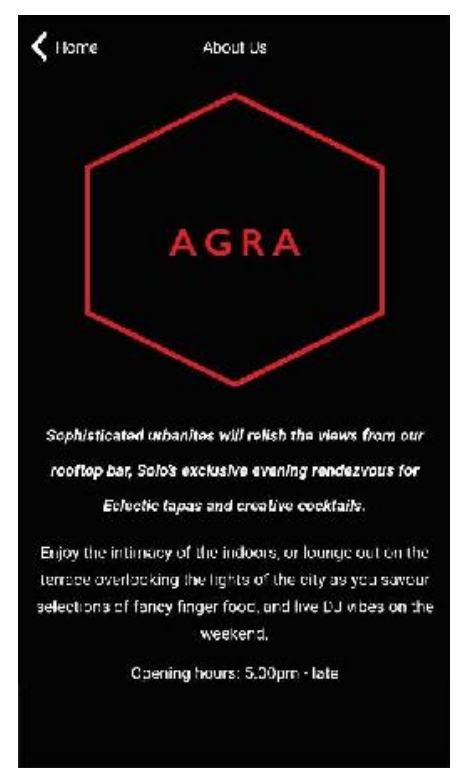

Gambar 16. Tampilan About Us [Sumber: Dokumentasi Penulis]

\section{Tahap Pengujian}

Tahap keempat penelitian ini adalah pengujian desain interface ini. Desain interface yang sudah jadi tersebut kemudian akan diujikan kepada beberapa staff dan tamu dari AGRA Rooftop. Berdasarkan pengujian kepada konsumen yang dilakukan dengan cara memberikan kuesioner kepada 40 konsumen secara acak di AGRA Rooftop. Materi yang diujikan meliputi layout, dan kejelasan materi yang ada dalam layout tersebut. Daftar pertanyaan yang diajukan kepada konsumen dapat dilihat pada Tabel 1.

Tabel 1. Daftar Pertanyaan Kuesioner [Sumber: Dokumentasi Penulis

\begin{tabular}{|c|c|c|c|c|c|c|}
\hline \multirow[t]{2}{*}{ No. } & \multirow{2}{*}{ Daftar Pertanyaan } & \multicolumn{5}{|c|}{ Jawaban } \\
\hline & & $\begin{array}{l}\text { San } \\
\text { gat } \\
\text { Set } \\
\text { uju }\end{array}$ & $\begin{array}{l}\text { Set } \\
\text { uju }\end{array}$ & $\begin{array}{l}\mathrm{Cu} \\
\text { kup }\end{array}$ & $\begin{array}{l}\mathrm{Ku} \\
\text { ran } \\
\mathrm{g} \\
\text { Set } \\
\text { uju }\end{array}$ & $\begin{array}{l}\text { Sang } \\
\text { at } \\
\text { Tidak } \\
\text { Setuj } \\
\text { u }\end{array}$ \\
\hline 1 & $\begin{array}{l}\text { Apakah menurut } \\
\text { anda background di } \\
\text { menu utama sudah } \\
\text { dapat } \\
\text { menggambarkan } \\
\text { area AGRA } \\
\text { Rooftop? }\end{array}$ & & & & & \\
\hline 2 & $\begin{array}{l}\text { Apakah icon yang } \\
\text { ada di menu utama } \\
\text { dapat } \\
\text { menggambarkan } \\
\text { identitas milik } \\
\text { AGRA Rooftop? }\end{array}$ & & & & & \\
\hline 3 & $\begin{array}{l}\text { Apakah informasi } \\
\text { yang ada di menu } \\
\text { utama dapat anda } \\
\text { pahami? }\end{array}$ & & & & & \\
\hline 4 & $\begin{array}{l}\text { Apakah menurut } \\
\text { anda tampilan pada } \\
\text { bagian sub menu dan } \\
\text { menu didalamnya } \\
\text { mudah dipahami? }\end{array}$ & & & & & \\
\hline
\end{tabular}




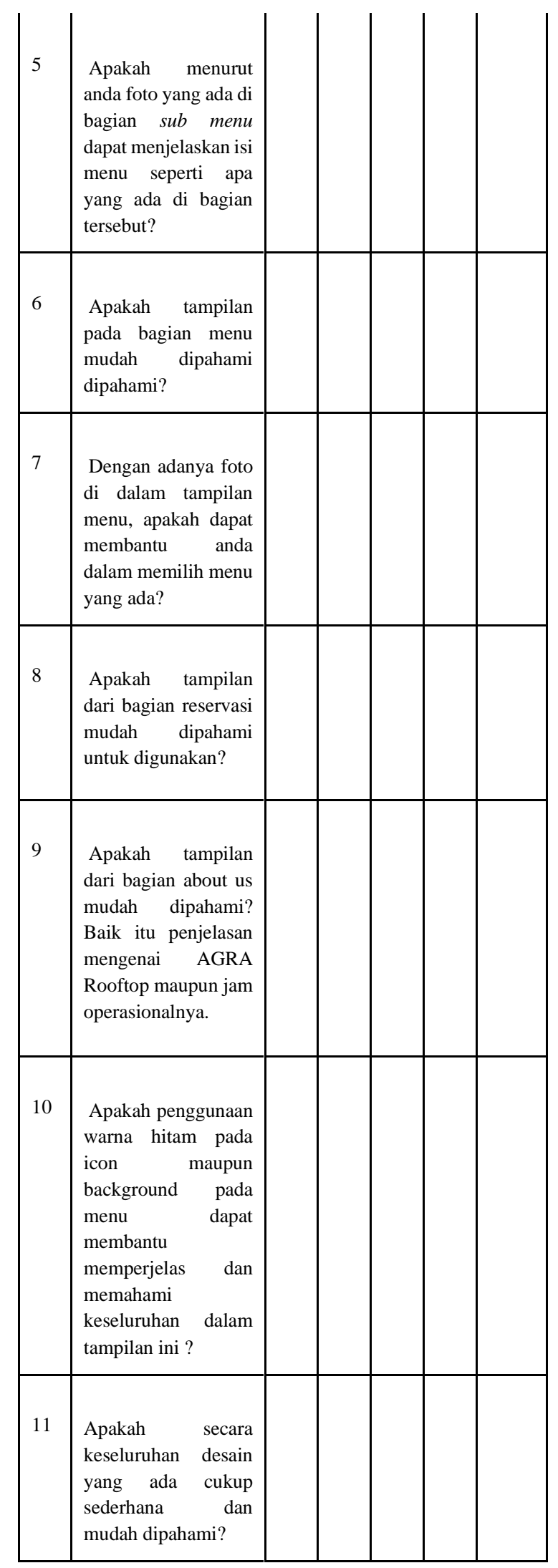

Penilaian yang diterapkan sebagai berikut :
Tabel 2. Daftar Point Penilaian Jawaban Kuesioner

\begin{tabular}{|l|l|}
\hline Skor & Keterangan \\
\hline 1 Point & Tidak Setuju \\
\hline 2 Point & Kurang Setuju \\
\hline 3 Point & Cukup \\
\hline 4 Point & Setuju \\
\hline 5 Point & Sangat Setuju \\
\hline
\end{tabular}

Berikut kriteria interpretasi skornya berdasarkan interval:

Tabel 3. Interval Persentase Penilaian

\begin{tabular}{|l|l|}
\hline Persentase & Keterangan \\
\hline $0 \%-19,99 \%$ & Sangat tidak setuju \\
\hline $20 \%-39,99 \%$ & Tidak setuju \\
\hline $40 \%-59,99 \%$ & Cukup \\
\hline $60 \%-79,99 \%$ & Setuju \\
\hline $80 \%-100 \%$ & Sangat setuju \\
\hline
\end{tabular}

Berikut rangkuman hasil penilaian 40 responden dari 11 pertanyaan tersebut.

Tabel 4. Hasil Jawaban Kuesioner

[Sumber: Dokumentasi Penulis]

\begin{tabular}{|l|c|}
\hline Jawaban Responden & Jumlah Jawaban \\
\hline Sangat tidak setuju & 1 \\
\hline Tidak setuju & 7 \\
\hline Cukup & 66 \\
\hline Setuju & 215 \\
\hline Sangat setuju & 151 \\
\hline
\end{tabular}

Maka penilaian interpretasi responden terhadap layout desain tersebut dihitung berdasarkan skala likert adalah :

Total skor $/ \mathrm{Y} \times 100=1828 / 2200 \times 100$ $=83.0 \%$

Berdasarkan hasil tersebut perancangan layout ini berada dalam kategori sangat setuju menarik dan mudah dipahami oleh konsumen.

Pengujian wawancara yang kedua dilakukan kepada staf di AGRA Rooftop dengan pertanyaan yang sama. Hasil yang didapat yaitu dari segi desain cukup mudah dipahami dan cukup menarik. Terdapat saran apabila aplikasi ini bisa di 
koneksikan dengan aplikasi yang sudah dimiliki AGRA Rooftop akan dapat lebih mempersingkat waktu sehingga orderan dari meja tamu dapat langsung diteruskan ke bagian dapur.

Pengujian wawancara yang ketiga dilakukan kepada Bapak Yusna Ardiansyah selaku outlet manager di AGRA Rooftop. Hasil yang didapat yaitu desain secara keseluruhan sudah cukup menarik dan merupakan suatu inovasi untuk AGRA Rooftop untuk mengenalkan menu dan mempromosikan event yang ada di AGRA Rooftop. Terdapat masukan untuk desain menu utama, akan lebih menarik jika dibuat layout lain supaya area AGRA Rooftop yang menjadi latar belakang dapat lebih ditonjolkan.

Dari hasil beberapa pengujian wawancara yang sudah dilakukan didapatkan hasil yang saling berhubungan yaitu layout yang sudah ada cukup menarik, dan kejelasan materi dapat diperoleh ke konsumen yang nantinya akan menggunakan aplikasi tersebut.

\section{KESIMPULAN}

Kesimpulan yang didapat pada perancangan desain interface untuk aplikasi menu AGRA Rooftop sudah cukup menarik, mudah dipahami oleh konsumen. Kejelasan materi dalam layout yang ada sudah dapat dipahami oleh konsumen maupun oleh tim dari AGRA Rooftop. Untuk selanjutnya dapat dikembangkan sebagai inovasi untuk menu maupun media promosi dari AGRA Rooftop.

\section{DAFTAR PUSTAKA}

Pramudita, Wisnu; dkk. 2014. Perancangan dan Implementasi Aplikasi Katalog Digital Dalam Pemilihan Busana Berbasis Multimedia ( Studi Kasus : Meercut Distro \& Clothing ). Salatiga: Universitas Kristen Satya Wacana

Andre Christian. 2013. Perancangan Aplikasi Katalog Penjualan Furniture Dengan Memanfaatkan Teknologi Augmented Reality Pada Android Platform. Salatiga: Universitas Kristen Satya Wacana
Kintar, Kusnawi. 2015. Implementasi UI dan UX Design Pada Website PT. TIME EXCELINDO. Yogyakarta : Teknik Informatika STMIK AMIKOM Yogyakarta

Sarwono, Jonathan dan Lubis. 2007. Metode Riset untuk Desain Komunikasi Visual. Yogyakarta: CV. Andi Offset 